\title{
Regeneration ability analysis of closely related doubled haploids of rapeseed (Brassica napus ssp. oleifera).
}

\author{
Anna Turczynowska \\ (INDEX: 28-33/2010 Copernican Letters ${ }^{\circledR}$ Vol 1 \\ Poznan University of Life Sciences \\ anturczy@up.poznan.pl
}

\begin{abstract}
Rapeseed (Brassica napus ssp. oleifera) is described mostly as a good source of plant material to conduct in vitro cultures, however the species reveal considerable genotypic diversity concerning regeneration ability. The aim of this experiment was to analyze regeneration capacity of eleven closely related rapeseed doubled haploid lines under in vitro conditions. Cotyledons and hypocotyls were incubated on a standard MS medium with the addition of $10 \mathrm{mg} / \mathrm{l}$ indole-3-butyric acid. MS medium without auxin was used as the control. Regeneration assessment was done after 28 days of culture. Genotypic variety regarding regeneration effectiveness was observed among the tested DH lines. Statistical tests showed significant differences in shoot regeneration in 4 out of 11 DH line pairs incubated on the control medium and in 8 pairs incubated on the medium containing phytohormone. Closely related DH lines revealing significant genotypic shoot regeneration diversity may be useful in further research on the genetic background of rapeseed regeneration ability under in vitro conditions.
\end{abstract}

\section{Introduction}

Regeneration is a prerequisite in the process of obtaining plants under in vitro conditions.

Technically, the induction of a regeneration process is very simple to perform, but the following precondition must be fulfilled. The explant containing totipotent cells should originate from a plant whose genotype has a strong potential to regenerate. The use of proper varieties of a given plant species may ensure success of a project. The literature on the subject names numerous varieties of different kinds of plants which are useful in regeneration processes under in vitro culture. Basing his decision on the data coming from the literature, the experimenter may choose a crop variety which in his opinion will be the best initial plant material to start the in vitro culture [1]. Nevertheless, plant regeneration abilities vary significantly between species, as well as between genotypes within the same species [2]. Intra-varietal variability of the organogenetic and callogenic response to plant growth regulators used in regeneration induction may be as great as the variability between species [3]. Species of the genus Brassica are characterized as easily regenerating [4]. However, it is very common among species generally known as well-regenerating that a considerable number of genotypes are resistant to regeneration induction. On the one hand, rapeseed (Brassica napus ssp. oleifera) is commonly considered as a good source of material to conduct in vitro culture, but on the other hand, within the species itself a substantial genotypic variability concerning regeneration capacity can be observed.

The aim of this research was to analyze regeneration ability of eleven closely related rapeseed double haploid lines under in vitro conditions on an MS medium with the addition of indole-3-butyric acid.

\section{Material \& Methods}

The plant material used in the study were cotyledonous and hypocotylous explants which originated from eleven rapeseed (Brassica napus ssp. oleifera) doubled haploid lines obtained in anther culture form the crop varieties Wotan, 
Kana, and Bor, and from a single hybrid between DH-O-120 and C-1041 DH lines. Table no. 1 shows the origin and genetic similarity of $\mathrm{DH}$ lines used in the study. The plant material was obtained due to the cooperation with the Plant Breeding and Acclimatization Institute in Poznan.

\section{Table 1}

The origin and genetic similarity of rapeseed (Brassica napus ssp. oleifera) DH lines. Genetic similarity ratio (GS) was estimated by means of RAPD molecular markers.

\begin{tabular}{|l|l|l|}
\hline \multirow{2}{*}{ Origin } & DH lines & $\begin{array}{l}\text { Genetic similarity } \\
\text { (GS) }\end{array}$ \\
\hline \multirow{4}{*}{ WOTAN } & $\mathrm{W}-15$ & 0,89 \\
\hline & $\mathrm{W}-69$ & 0,92 \\
\hline & $\mathrm{W}-70$ & 0,93 \\
\hline $\mathrm{W}-78$ & 0,90 \\
\hline KANA & $\mathrm{K}-5$ & 0,71 \\
\hline \multirow{2}{*}{ BOR } & $\mathrm{K}-24$ & 0,52 \\
\hline Single hybrid \\
DH-O-120 x C-1041 & $\mathrm{B}-21$ & 0,93 \\
\hline & $\mathrm{H}-105$ & 0,87 \\
\hline & $\mathrm{H}-129$ & 0,51 \\
\hline
\end{tabular}

In order to obtain explants, grains of rapeseed were sterilized and incubated on a basic MS medium [5] according to the standard in vitro culture procedure. Subsequently, the grains were kept under appropriate light and temperature conditions for five days. Afterwards, hypocotylous and cotyledonous explants were extracted from young seedlings. The collected explants were incubated on the MS medium again, but this time (with the addition of) it contained $10 \mathrm{mg} / 1$ indole-3butyric acid (IBA). The control was MS medium without a growth regulator. In every plate 9 explants (6 cotyledons and 3 hypocotyls) originating from 3 seedlings were placed. The experiment was repeated three times and each replication included 45 explants from each line. Altogether, 2970 explants were incubated, out of which 990 were hypocotylous explants and 1980 cotyledonous explants.
Regeneration evaluation was performed after 28 days of culture. Regeneration effectiveness of $\mathrm{DH}$ lines was measured based on the proportion of shoot regenerating explants to the total number of explants used [6] according to the formula

$$
R E=S R E / T N E \times 100 \%
$$

where: $R E$ - regeneration effectiveness, SRE - shoot regenerating explants, TNE - Ftotal number of explants.

In order to determine significant differences in shoot regeneration between closely related $\mathrm{DH}$ lines statistical testing with the use of $\mathrm{R}$ application was used. Significant differences were examined at $p$ value $<0,05$ using Kruskal's test and at $\mathrm{p}$ value $<0,01$ using Student's test. Null hypothesis assumed mean identity for both samples which means that no significant differences in regeneration effectiveness between the two tested lines were observed whereas an alternative hypothesis assumed that means from these samples differed significantly. The difference in shoot regeneration effectiveness was considered as truly significant when $p$ value was smaller than the set confidence level both for the results from the control medium and for the results from the medium with the phytohormone.

\section{Results}

The tested DH lines showed genotypic diversity in the manner of explants regeneration on the applied medium types. Direct shoot and root formation as well as indirect explant regeneration via callus were observed on the edges of the extracted plant tissue. The presence of callus was observed in insignificant quantity on each type of the explants, but its formation was limited to the cut ends of plant tissue and expanded only in late phases of culture. Callus and adventitious root development were observed on the basal side of hypocotyls while shoots were rather formed on the apical end of hypocotyls. Only the 
explants from the K-5 line, incubated on the control medium, and the $\mathrm{W}-15$ line explants placed on the medium with the addition of IBA did not regenerate callus at all. Moreover, callus was observed neither on the control hypocotylous explant of the lines B-21 and K-24 nor on the control cotyledonous explants of the line W-15. On the control medium callus regenerated occasionally whereas on the medium with auxin it was formed approximately on $3 / 4$ of the explants tested.

Rhizogenesis was found on every cotyledonous explant which was incubated on the control medium, except for the $\mathrm{K}-5$ and B-18 line explants which did not form roots at all. The extent of rhisogenesis was, however, limited. Hypocotylous explants were forming roots on the control medium occasionally and only in case of three lines. On the medium with the addition of artificial auxin rhizogenesis was observed on all explants apart from the W-15 line which did not regenerate roots at all. On the medium with phytohormone rhizogenesis was observed on approximately $84.4 \%$ of the explants tested and on $21.3 \%$ of the explants from the control medium.

Shoots formation was considerably lower in comparison to rhizogenesis. The variability of shoot regeneration effectiveness on the medium with IBA ranged from $0 \%$ to $42 \%$ for the first replication (Fig.1), from $2.2 \%$ to $37.8 \%$ for the second replication (Fig.2) and from 0\% to $44.4 \%$ for the third replication of the experiment (Fig.3). Minimum and maximum on the control medium in the first, second and third replication of the experiment were $0 \%$ and $6.7 \%$ (Fig. 1 ), $0 \%$ and $8.9 \%$ (Fig. 2), and $0 \%$ and $13.3 \%$ (Fig. 3 ) respectively. Shoot regeneration effectiveness for the medium with IBA was $18.3 \%$ on average and was higher than the average shoot regeneration effectiveness on the control medium, which occurred occasionally on 3\% of the explants. Shoots regeneration of cotyledonous explants was observed only on the control medium. On the medium which contained IBA shoots regeneration was found in the majority of cotyledons. Nevertheless, hypocotylous explants incubated on the IBA medium were regenerating shoots only in $0.6 \%$ cases. The highest average shoot regeneration effectiveness was observed for the line H-396 on both types of the mediums. Repeatability of the research results remained the same during all replications of the experiment. Mean values of shoot regeneration obtained in the experiment are presented in figure no 4 .

\section{Figure 1}

Shoot regeneration effectiveness of the $\mathrm{DH}$ lines of rapeseed from the first testing on the control medium and the medium containing indole-3-butyric acid.

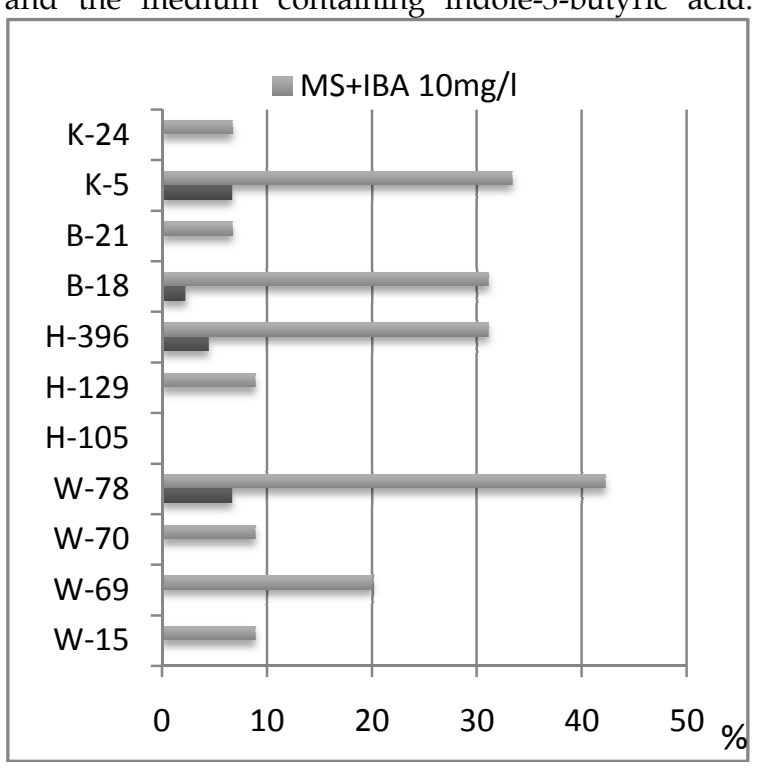




\section{Figure 2}

Shoot regeneration effectiveness of the $\mathrm{DH}$ lines of rapeseed from the second testing on the control medium and the medium containing indole-3-butyric acid.

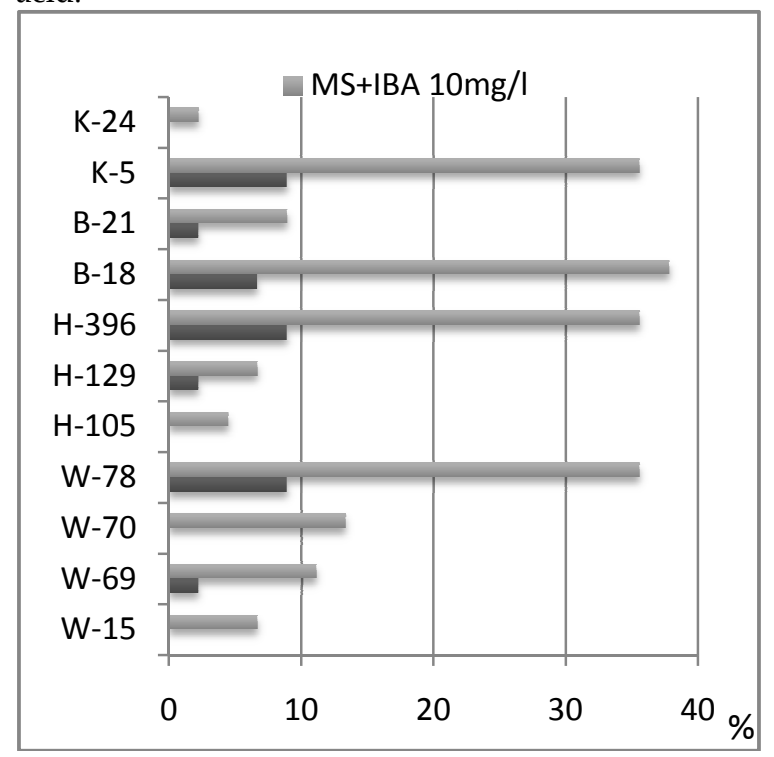

\section{Figure 3}

Shoot regeneration effectiveness of the $\mathrm{DH}$ lines of rapeseed from the third testing on the control medium and the medium containing indole-3-butyric acid.

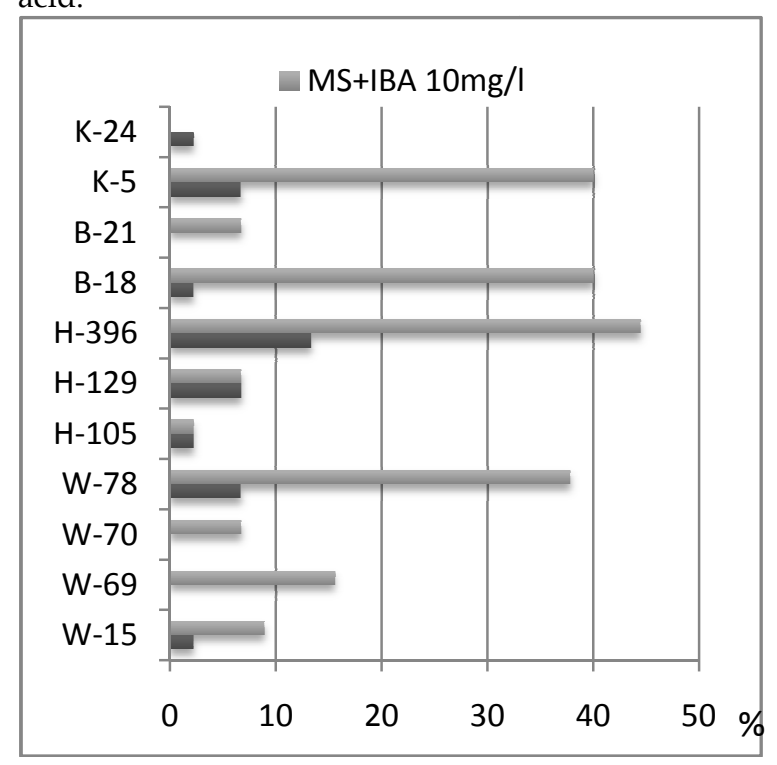

Figure 4

Average shoot regeneration effectiveness of the $\mathrm{DH}$ lines of rapeseed on the control medium and the medium containing indole-3-butyric acid.

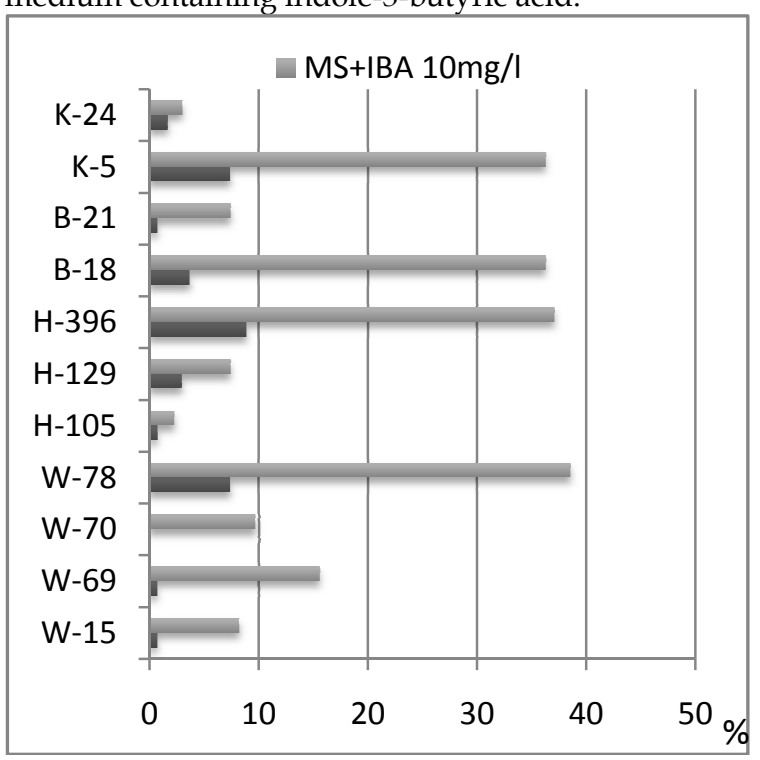

The Student's test conducted on samples regenerated on the medium with the addition of phytohormone and without it revealed significant differences in shoot regeneration effectiveness between the lines $\mathrm{W}-15$ and $\mathrm{W}-78, \mathrm{~W}-69$ and $\mathrm{W}-78$ as well as between the lines $\mathrm{W}-70$ and $\mathrm{W}-78$. The lines $\mathrm{K}-5$ and $\mathrm{K}-24$ also proved to be significantly different with respect to shoot regeneration both on the control medium and on the medium with IBA whereas between the lines H-105, H-129, and H-396 as well as between the lines B-18 and B-21 the Student's test indicated significant differences in shoot regeneration effectiveness only for samples incubated on the medium with the growth regulator. The Kruskal's test confirmed significant differences in shoot regeneration effectiveness between the lines $\mathrm{W}-15$ and $\mathrm{W}-78, \mathrm{~W}-69$ and $\mathrm{W}-78, \mathrm{~W}-70$ and $\mathrm{W}-78$ as well as between the lines K-5 and K24 on the control and tested medium. The same test showed significant differences in regeneration abilities on both kinds of medium for the lines H-105 and H-396. Nevertheless, for the pairs W-15 and W-69, H-105 and H-129 as well as for the pair H-129 and H-396 Kruskal's test revealed 
significant differences in shoot regeneration effectiveness only for samples incubated on the medium with the addition of phytohormone. P values from the Student's and Kruskal's tests are presented in table no 2.

\section{Table 2}

Differences in shoot regeneration effectiveness between the $\mathrm{DH}$ lines of the rapeseed incubated on the control medium and the medium with the addition of IBA. Significant differences in regeneration ability are indicated with the asterisk.

\begin{tabular}{|c|c|c|c|c|}
\hline \multirow[b]{2}{*}{$\begin{array}{l}\text { Compared } \\
\text { lines }\end{array}$} & \multicolumn{2}{|c|}{ Control medium MS } & \multicolumn{2}{|c|}{$\begin{array}{l}\text { Medium MS } \\
+ \text { IBA (10 mg/l) }\end{array}$} \\
\hline & $\begin{array}{l}\text { p value < } \\
0,05 \\
\text { Kruskal } \\
\text { test }\end{array}$ & $\begin{array}{l}\mathrm{p} \text { value < } \\
0,01 \\
\text { Student } \\
\text { test }\end{array}$ & $\begin{array}{l}\text { p value < } \\
0,05 \\
\text { Kruskal } \\
\text { test }\end{array}$ & $\begin{array}{l}\text { p value < } \\
0,01 \\
\text { Student } \\
\text { test }\end{array}$ \\
\hline W-15,W-69 & 1 & 1 & $0.046^{*}$ & 0.092 \\
\hline W-15,W-70 & 0.317 & 0.423 & 0.637 & 0.538 \\
\hline W-15,W-78 & $0.043^{*}$ & $0.003^{*}$ & $0.046^{*}$ & $0.002^{*}$ \\
\hline W-69,W-70 & 0.317 & 0.423 & 0.127 & 0.145 \\
\hline W-69,W-78 & $0.043^{*}$ & $0.003^{*}$ & $0.0495^{\star}$ & $0.003^{*}$ \\
\hline W-78,W-70 & $0.034^{*}$ & $0.010^{*}$ & $0.0495^{\star}$ & $0.0004^{*}$ \\
\hline H-105,H-129 & 0.346 & 0.379 & $0.046^{*}$ & $0.035^{*}$ \\
\hline H-105,H-396 & $0.046^{*}$ & 0.077 & $0.0495^{*}$ & $0.007^{*}$ \\
\hline H-129,H-396 & 0.127 & 0.146 & $0.046^{*}$ & $0.015^{\star}$ \\
\hline B-18,B-21 & 0.099 & 0.174 & $0.046^{*}$ & $0.005^{*}$ \\
\hline K-5,K-24 & $0.043^{*}$ & $0.003^{*}$ & $0.0495^{\star}$ & $0.0003^{*}$ \\
\hline
\end{tabular}

\section{Discussion}

Different genetic factors, plant's growth stage and condition as well as environmental factors such as medium chemistry, growth regulators, light, temperature, and interactions between them influence regeneration and proliferation of plant cells under in vitro culture $[4,7,8]$.

The reaction of explants to different culture in vitro conditions may vary. Identical genotypes incubated in similar conditions often respond differently. The response may result from specific requirements of an individual concerning culture conditions and from greater or lesser regeneration abilities of a plant [4].

Among many factors influencing the success of a regeneration process under in vitro culture, the genotype seems to play the most important role [9].
The differences existing in shoot regeneration abilities between explants originating from different genotypes of one variety show that the regeneration process in the species Brassica napus is highly variable and genotype-specific [10].

In this paper differences in shoot regeneration effectiveness between four doubled haploid pairs on a control medium, and as many as eight on a medium with the addition of indole-3butyric acid were observed. Full control over temperature, light and medium chemistry conditions as well as repeatability of the research results indicate that there might exist an important genotypic variation among the $\mathrm{DH}$ lines tested. Statistical testing allowed to detect significant differences between the following doubled haploid pairs: $\mathrm{W}-15$ and $\mathrm{W}-78, \mathrm{~W}-69$ and $\mathrm{W}-78, \mathrm{~W}-70$ and $\mathrm{W}-78$ as well as K-5 and K-24 on both the control medium and the medium containing phytohormone.

Similar results were presented in the paper by Burbulis et al. [9], where significant differences in callus induction and plant regeneration were observed among three DH lines. In these research hypocotylous explants of the lines NL-611 and NL-662 displayed greater ability to form shoots than the line NL-685 on a medium containing $4 \mathrm{mg} / \mathrm{l} \mathrm{BAP}$ and 0.05 mg/l NAA.

Similar results were obtained when examining other species of the genus Brassica, for expample B. campestris [11], B. oleraceae [12], and B. rapa [13].

These results confirm earlier reports regarding regeneration capacity in the species Brassica napus [14, 15, 16] and point to the importance of genotype in shoot regeneration.

The use of both genotypes resistant and susceptible to identical conditions of in vitro culture within the same genus may simplify genetic research [17].

Closely related doubled haploids revealing significant genotypic variation in 
shoot regeneration among each other may be a useful tool in the study of genetic background concerning regeneration ability under in vitro conditions in the species Brassica napus ssp. oleifera.

\section{Summary}

The experiment indicated a significant variation existing among closely related doubled haploid lines of rapeseed. Such lines may be useful in the study of the genetic background of regeneration ability in important crops such as rapeseed. However, regeneration ability of plants is a complex feature, highly influenced by different genetic and environmental factors. Further and more detailed research is needed in order to fully understand the genetic background of regeneration capacity in rapeseed explants kept under in vitro conditions.

\section{REFERENCES}

[1] J. Buchowicz, „Biotechnologia molekularna. Modyfikacje genetyczne, postępy, problemy.", 2009, Wydawnictwo Naukowe PWN.

[2] P.S. Jourdan, E.D. Earle, "Genotypic variability in the frequency of plant regeneration from leaf protoplasts of four Brassica ssp. and Raphanus sativus." 1989, p. 343-349, Journal of the American Society for Horticultural Science no 114.

[3] M.F. Dietert, S.A. Barron, O.C.Yoder, "Effects of genotype on in vitro culture in the genus Brassica.", 1982, p. 233-240, Plant Science Letters no 26.

[4] A. Wojciechowski, „Zdolności regeneracyjne wybranych genotypów Brassica w kulturach in vitro.", 1998, Roczniki Akademii Rolniczej w Poznaniu. Rozprawy naukowe. Zeszyt no 289.

[5] T. Murashige, F. Skoog, "A revised medium for rapid growth and bioassays with tobacco tissue cultures.", 1962, p. 437- 497, Physiol. Plant. no 15.

[6] J. Zandecka-Dziubak, T. Łuczkiewicz, „Efektywność embriogenezy somatycznej w kulturach in vitro lnianki siewnej (Camelina sativa L.).", 2000, p. 615-620, Oilseed Crops no XXI (2).

[7] H. Bolibok, M. Rakoczy-Trojanowska, "Genetic mapping of QTLs for tissue-culture response in plants.", 2006, p. 73-83, Euphytica no 149.

[8] A. Woźny, K. Przybył, „Komórki roślinne w warunkach stresu t. II: Komórki in vitro", 2004, p. 167 Poznań: Wydawnictwo Naukowe U AM

[9] N. Burbulis, R. Kupriene, A. Blinstrubiene, "Callus induction and plant regeneration from somatic tissue in spring rapeseed (Brassica napus L.)", 2008, p. 258263, Biologija no 54 (4).
[10] M. R. Khan, H. Ramzan, A. Rashid Quraishi, "High Frequency Shoot Regeneration from Hypocotyl of. Canola (Brassica napus L.) cv. Dunkled.", 2002, p. 131-138, Plant Tissue Cult. no 12(2).

[11] F.L. Zhang, Y. Takahata, J.B. Xu, 1998, p. 780-786, Plant Cell Rep. no 17.

[12] E.C. Pua, X. Deng, T.C. Koha, 1999, p. 598-605, J. Plant Physiol. no 155.

[13] G.X. Tang, W.J. Zhou, H.Z. Li et al., 2003, p. 351358, J. Agron. Crop. Sci. no 189.

[14] G.B. Kamal , K.G. Illich, A . Asadollah, 2007, p. 861- 867Afr. J. Biotech nol. no 6(7).

[15] Y. Akasaka-Kennedy, H. Yoshida, Y. Takahata, 2005, p. 649-654, Plant Cell Rep. no 24.

[16] A.B. Ghnaya, G. Charles, M. Branchard, 2008, p. 25-30, Plant Cell Tiss. Organ. Cult. no 92.

[17] J. Julliard, L. Sossountzov, Y. Habricot, G. Pelletier, "Hormonal requirement and tissue competency for shoot organogenesis in two cultivars of Brassica napus.", 1992, p. 521-530, Physiol. Plant no 84 . 